\title{
Analysis of activation features of geodynamic processes and formation of impact hazard at Nikolaevsk deposit
}

\author{
Aleksandr Sidlyar ${ }^{1 *}$, Boris Saksin ${ }^{l}$, Marina Potapchuk ${ }^{l}$, Vitaliy Usikov ${ }^{l}$ and Mikhail Lo- \\ mov $^{l}$ \\ ${ }^{1}$ Mining Institute of the Far Eastern Branch of the Russian Academy of Sciences, 680000, 51, Turge- \\ nev st., Khabarovsk, Russian Federation
}

\begin{abstract}
Based on the results of a joint analysis of seismic-acoustic monitoring data and the geological and structural features of the Nikolaevsk deposit, the main regularities of the formation of technogenic stress fields that determine its impact hazard have been identified. Additionally, using the method of mathematical modeling, a study was done of the stress-strain state of the rock mass taking into account the tectonically active fault TD-3 and safety measures were proposed to reduce the impact hazard of the rock mass at the Nikolaevsk deposit.
\end{abstract}

\section{Introduction}

The problem of impact hazard in underground mines of the Far Eastern region has not lost its relevance for several decades. Rock pressure, which is unavoidable during underground mining in deep horizons and at a high tectonic tension of the massif, poses a serious threat to the life of workers, disrupts the normal course of mining operations and thereby reduces the efficiency of mining $[1,2]$.

Among the most dangerous deposits of the Far East of Russia is the Nikolaevsk polymetallic deposit located in Primorsk Territory in the city of Dalnegorsk. The deposit is characterized by a complex geological structure and confined to tectonically active areas of the Earth's crust [3].

Since 2011, over 250 dynamic manifestations of rock pressure in various forms have been recorded at the deposit, from rock outbursts to rock bursts and tectonic impacts. Due to the operational use of geomechanical monitoring and timely relief measures at the Nikolaevsk deposit in recent years, it has been possible to significantly reduce the number of dynamic manifestations compared with 2011 -2012 (Fig. 1).

*Corresponding author: alex-igd@mail.ru 


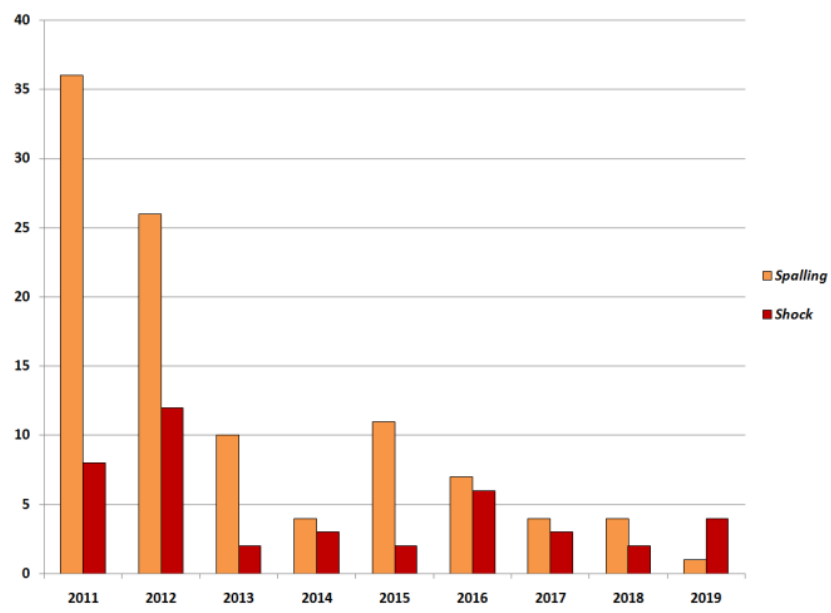

Fig. 1. The distribution of the number of dynamic manifestations of rock pressure (shocks and spallings) at the Nikolaevsk deposit in $2011-2019$.

\section{Results of a joint analysis of seismic-acoustic monitoring data and geological and structural features}

Despite the fact that by 2011 the field experienced a slight decline in the number of manifestations of rock pressure (Fig. 1), the most destructive events were recorded in 2015 - 2016. They were accompanied by powerful sound effects, shaking of the entire mine field and seismic vibrations noted at the surface site of the mine. As a result of these phenomena, the supports and the contours of the mine workings were destroyed at horizons $-433,-420,-406,-390,-375,-360$ where mining operations were underway.

On March 25, 2016 the Prognoz-ADS system [4] a few seconds after recording of an earthquake with a magnitude of 4 points in the community of Kamenka, located on the coast of the Sea of Japan $15 \mathrm{~km}$ from the city of Dalnegorsk, recorded a major geodynamic event, which led to the formation of open fractures and cracks in the massif of rocks up to tens of meters. At the boundaries of the gaps, soil elevations of $10-12 \mathrm{~cm}$ were observed.

The solution to the problem of rock pressure control is largely constrained by the insufficient knowledge of the nature and mechanism of geodynamic processes and phenomena that occur in the rock mass under the influence of numerous natural and technogenic factors. Under the current conditions, more in-depth comprehensive studies are needed, including an assessment of the geodynamic and seismic conditions, as well as the stress-strain state of the massif.

At the Nikolaevsk deposit, impact hazard assessment and control are carried out by instrumental measurements of the parameters of seismic-acoustic activity of rock massifs using the Prognoz-ADS digital geoacoustic monitoring system and the Prognoz-L local monitoring device, as well as systematic visual observations of dynamic manifestations of rock pressure in mine workings. The PrognozADS automated rock pressure monitoring system (ARPMS) used for the regional impact hazard forecast provides effective recording of acoustic signals, their digitization, processing and transmission via digital communication channels to the central computer from which the measurement and computing assembly are controlled $[5,6]$.

To date, the observational network includes 31 digital receiving transducers (DRTs) installed in wells drilled from the mine workings at horizons $-307,-323,-348,-360,-380,-390,-406,-420$ and $433 \mathrm{~m}$.

In total, during the observation period since 2011, the Prognoz-ADS geoacoustic monitoring system recorded more than 42,000 AE events. An analysis of the results of seismic-acoustic observations showed that most of them are confined to mining operations sites, as well as to the faults network, and especially to the zone of tectonically active steeply pitching fault TD-3 (Fig. 2). The site of the mine 
field on the southern and northeastern flank of the deposit was characterized by the highest seismoacoustic activity.

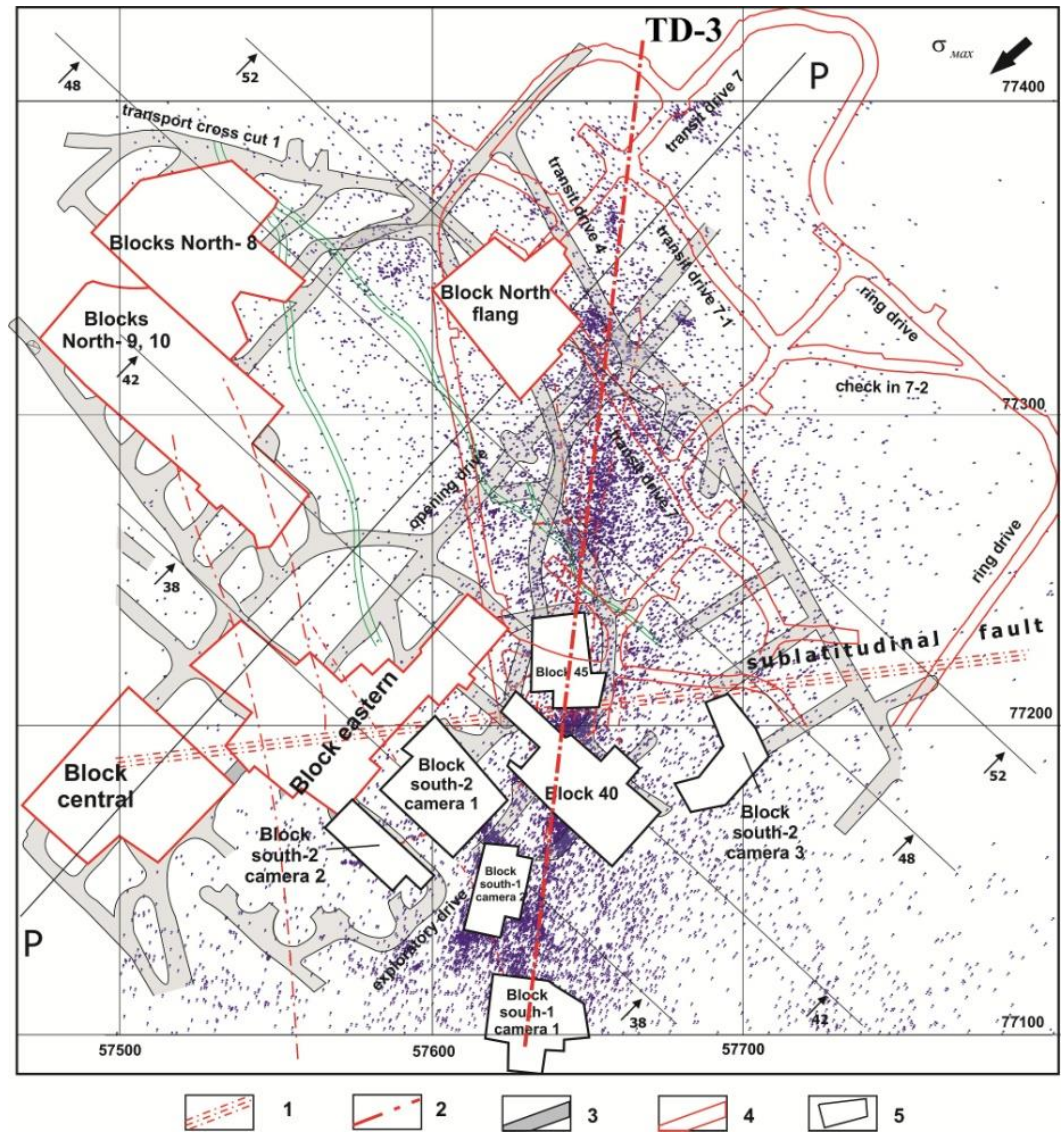

1 - block-forming sublatitudinal fault; 2 - tectonic disturbances; 3 - workings completed at $-390 \mathrm{~m}$ horizon; 4 - workings completed at -420 m horizon; 5 - worked out space of treatment chambers

Fig. 2. Map of the acoustic activity of the Nikolaevsk deposit's massif according to seismoacoustic control in $2011-2019$

The analysis of large dynamic manifestations shows a similar picture. Over the observation period since 2011, the Prognoz-ADS system recorded 35 shocks at the deposit The largest number of them is confined to the fault network, and especially to the zone of the active steeply pitching submeridional fracture TD-3 with accompanying fracturing systems, especially at the points of its intersection with steeply pitching dyke bodies of diabase porphyrites, mainly of the northwest direction (Fig. 2). This structure is a zone of increased fracturing up to a width of $50-60 \mathrm{~m}$ with dispersed sulfide mineralization and separate crushing zones.

Additionally, the results of geomechanical monitoring were compared with the peculiarities of the tectonic structure of the Nikolaevsk deposit. Maps of isohypses of all main rock contours were built. According to the results of studying the geological and structural features, it was revealed that the main heterogeneity of the geological environment of the ore field, which determines its modern structure, as well as the features of the SSS, is a large inclined limestone plate (olistolith). As mentioned earlier, the geodynamic event that occurred on March 25, 2016, led to the formation of open fractures and cracks in the rock massif, several tens of meters long. The locations of the gaps and open cracks were plotted (Fig. 3) and also spatially coincided with the outline of the body of the limestone olistolith and elements of the tectonic structure of the deposit. 


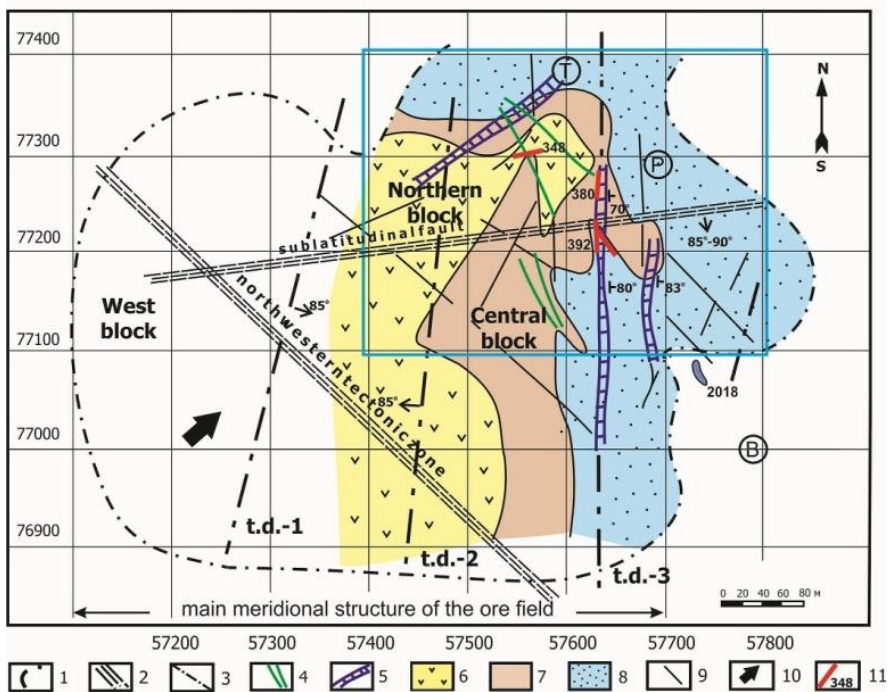

1 - projection of the contour of olistolith on a horizontal plane; 2 - block-forming faults and their names; 3 - other tectonic disturbances and their numbers; 4 - dykes of medium and basic composition; 5 - gorges in the body of limestone filled with metasomatites;

6 - relatively geodynamically stable region; 7 - gently sloping area with intermediate geodynamic activity; 8 - geodynamic region formed by morphological features of olistolith and modern stress field; 9 - lineaments of the relief of olistolith roof; 10 - direction of the main horizontal compression of the rock mass; 11 -location of gaps and open cracks formed by the earthquake of March 25, 2016

Fig. 3. Block structure of the body of the olistolith of ore-bearing milestones of the Nikolaevsk deposit and its modern geodynamic zoning

\section{Modeling of the stress-strain state of a rock mass taking into account the TD-3 fault}

The influence of the tectonically active fault TD-3 on the level of the stress-strain state of the rock mass was estimated using numerical methods, in particular, the finite element method [7].

The simulation was carried out in a flat statement of the problem in projection onto a horizon of $390 \mathrm{~m}$ in the actual situation at the mine, taking into account the worn treatment chambers.

In rationalizing the boundary conditions, the results of previous geomechanical studies were used, according to which it was found that in the massif of the Nikolaevsk deposit there is an unequal component stress field, in which horizontal tectonic stresses prevail 1.5-2.5 times higher than the vertical gravity component. The stress-strain state of the flat region of rock mass was calculated under the following boundary conditions: depth of $770 \mathrm{~m}$ from the surface (mark $-390 \mathrm{~m}$ ), the first principal stresses (X coordinate) were taken equal to $\sigma_{l}=31.69 \mathrm{MPa}$, the second principal stresses ( $\mathrm{Y}$ coordinate) were taken equal to $\sigma_{2}=52.83 \mathrm{MPa}$. The shear components were taken equal to 0 .

The physic-mechanical properties of the rocks and ores of the deposit, adopted in the simulation of the FEM, were established by previously conducted laboratory studies (see Table 1). Almost the entire lithological complex of the host rocks and ores has a sufficiently high strength and, at the same time, is characterized by increased values of the impact hazard coefficient $\left(K_{\text {imp }}=\varepsilon_{\text {impstr }} / \varepsilon_{\text {total }}>0.7\right)$, which gives grounds to consider them potentially impact hazardous, capable of accumulating significant potential energy and collapse in dynamic form. 
Table 1. Strength properties of rocks used in modeling

\begin{tabular}{|c|c|c|c|c|c|c|c|c|}
\hline \multirow{2}{*}{ Name of rocks } & $\begin{array}{c}\text { Ultimate } \\
\text { compression } \\
\text { strength, MPa }\end{array}$ & \multirow{2}{*}{$\begin{array}{c}\text { Density, } \\
\mathrm{kg} / \mathrm{m}^{3}\end{array}$} & $\begin{array}{c}\text { Stress-strain modu- } \\
\text { lus } E, \mathrm{MPa}\end{array}$ & $\begin{array}{c}\text { Poisson's } \\
\text { ratio }\end{array}$ & $\begin{array}{c}\text { Tensile } \\
\text { strength, } \\
\text { MPa }\end{array}$ & $\begin{array}{c}\text { Angle of } \\
\text { internal } \\
\text { friction, deg. }\end{array}$ & $\begin{array}{c}\text { Coherency } \\
\mathrm{C}, \mathrm{MPa}\end{array}$ \\
\hline \multicolumn{7}{|c|}{ Ore } \\
\hline Hedenbergite skarn & 135.2 & 3,400 & 54,400 & 0.25 & 8.4 & 41.5 & 7.9 \\
\hline \multicolumn{7}{|c|}{ Host rocks } \\
\hline Limestone & 99.0 & 2,750 & 49,400 & 0.20 & 4.7 & 42 & 10 \\
\hline $\begin{array}{c}\text { Quartz-porphyry } \\
\text { tuffs }\end{array}$ & 99.6 & 2,650 & 65,000 & 0.24 & 8.3 & 41.5 & 6.5 \\
\hline Sandstone & 105.1 & 2,850 & 46,600 & 0.27 & 5.7 & 39.5 & 5.2 \\
\hline
\end{tabular}

The calculation results were analyzed in the form of isolines of average normal stresses (mean pressure) $\sigma_{a v}$, shear stress intensities $\tau_{i n t}$, principal normal stresses $\left(\sigma_{1}, \sigma_{2}\right)$ and horizontal $\sigma_{x}$ and $\sigma_{y}$ components of the stress tensor.

Figure 4 shows the simulation results excluding the TD-3 fault (left) and taking into account the TD-3 fault (right).

A)

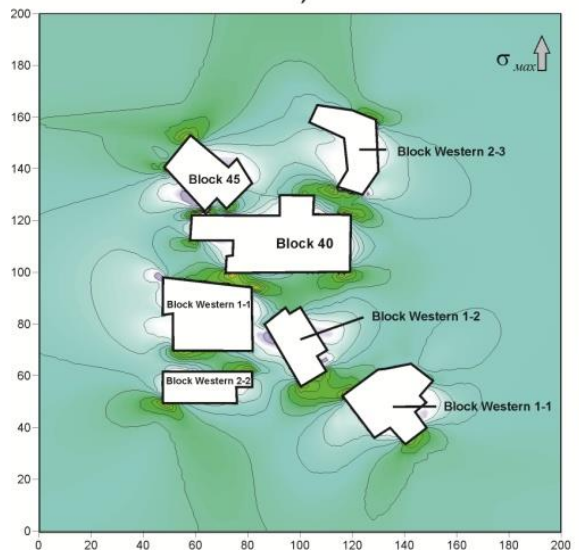

B)

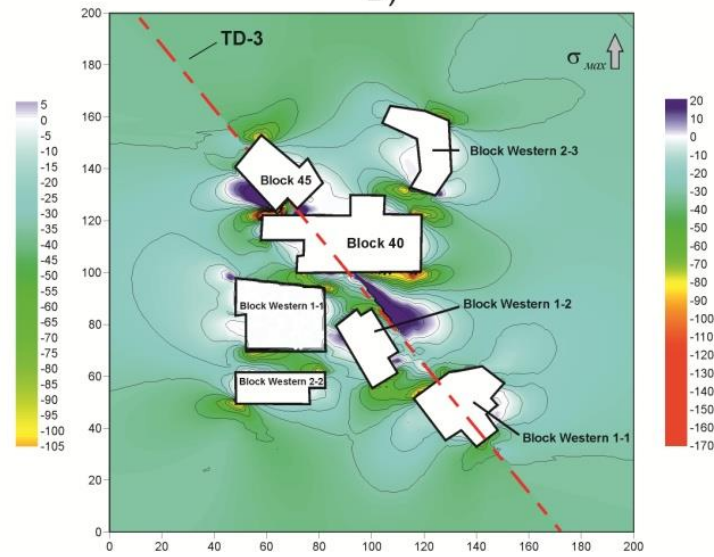

Fig. 4. Distribution of horizontal stresses Sy in the projection on to the horizons $-390 \mathrm{~m}$ of the Vostok ore deposit (A - excluding theTD-3 fault, B - taking into account the TD-3 fault)

An analysis of the simulation results showed that the tectonically active fault TD-3 has a significant effect on the formation of high stress concentrations during mining of the Vostok-1 ore deposit section in the region of the chambers located along this fault (chamber 2 Southern-1, blocks 40 and 45). In the zone between the worked out space of blocks 40 and 45 in the area of the TD-3 fault, there is a 2 -fold increase in compressive stresses and a 6-fold increase in tensile stresses, significantly exceeding the maximum allowable compressive and tensile strength limits of the enclosing rocks.

The simulation results correlate well with the data of seismic-acoustic monitoring and confirm that the TD-3 fault is a factor significantly affecting and increasing the degree of impact hazard in the region of its occurrence in the structure of the Nikolaevsk deposit. In this regard, it is necessary to develop additional safety measures to reduce the influence of the TD-3 fault on the formation of high stress concentrations and the impact hazard of the rock mass $[8,9]$.

In the authors' opinion, the only and most effective way to reduce the impact hazard at the Nikolaevsk field in the influence zone of TD-3 is to fill waste chambers with hardening mixtures. It is proposed to fill not all waste chambers, but only those located at the intersection with the TD-3 fault. According to calculations, this amounts to about $25-30 \%$ of the total volume of worked out space. The simulation results show that the filling of the mined-out space of waste chamber 1 of Southern-1 block, and blocks 40 and 45 (gray in Fig. 5b) with cement mixtures, allows reducing the concentration of compressive stresses to the maximum permissible values (90 MPa and lower ) (Fig. 5). 
A)

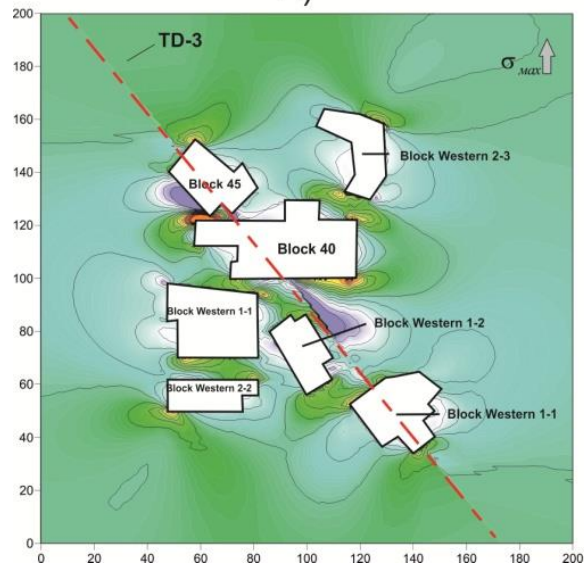

B)

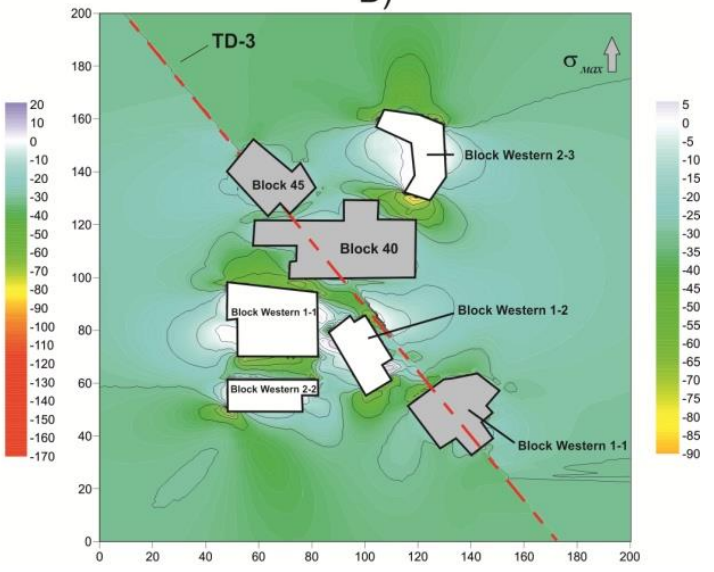

Fig. 5. Distribution of horizontal stresses Sy in the projection onto the horizons $-390 \mathrm{~m}$ of the Vostok ore deposit (A - the actual option for mining the chambers, B - the proposed option for mining, taking into account the hardening mixture filling of the chambers located along TD-3)

\section{Conclusions}

1. The features of the manifestation of acoustic activity in the massif of rocks at the Nikolaevsk deposit at the stage of formation of potentially impact hazardous zones have been revealed. The largest number of recorded seismic-acoustic events, including shocks and tectonic rock impacts, is confined to the fault network, and especially to the zone of active steeply dipping submeridional fault TD-3.

2. Based on the results of studying the geological and structural features of the skarn-polymetallic Nikolaevsk deposit, it was found that the main heterogeneity of the geological environment of the ore field, which determines its modern structure, as well as the peculiarities of the VAT of the rock mass, is a large oblique bed of limestone (olistolith). The constructed consolidated block diagram of limestone olistolith allows one to identify potentially hazardous areas in advance and more reliably interpret seismic-acoustic monitoring data reflecting geomechanical processes in the developed rock mass.

3. The effect of the tectonically active fault TD-3 on the level of the stress-strain state of the rock mass by the finite element method has been evaluated. The simulation results correlate with the seismic-acoustic monitoring data and confirm that this structural element has a significant effect on the formation of high stress concentrations during mining of the Vostok-1 ore deposit section.

4. As an additional safety measure to reduce the impact hazard of the massif of rocks of the Nikolaevsk deposit, it is proposed to fillwaste chambers located at the intersection with the TD-3 faultwith solidified mixtures. The simulation results showed that this measure will reduce the level of concentration of compressive stresses to the maximum permissible values ( $90 \mathrm{MPa}$ and below).

\section{References}

1. M. Henryk, G. Z. Mutke. Journal of Seismology (2013). Vol. 17. No 4. P. 1139-1148.

2. P. E. Snelling, L. Godin, S. D. McKinnon. International Journal of Rock Mechanics and Mining Sciences. - Vol. 58. - February (2013). - P. 166-179.

3. M. I. Potapchuk, G. A. Kursakin, Sidlyar A. V. Eurasian Mining (2014). No 1. P. 18-22.

4. A. V. Sidlyar, B. G. Saksin, P. A. Anikin, M. A. Lomov. Problems of complex development of georesources. Web of Conferences (2018)

5. I. Yu. Rasskazov, M. I. Potapchuk, G. A. Kursakin, Yu. I. Bolotin, A. V. Sidlyar, M. I. Rasskazov. Mining Information and Analytical Bulletin. - (2012). - No. 4. -P. 96-102 [In Russian].

6. M. I. Potapchuk, I. Yu. Rasskazov, G. M. Potapchuk, A. V. Sidlyar, M. I. Rasskazov. Problems of integrated development of geo-resources: materials of the IV All-Russian Scientific Conference 
with the participation of foreign scientists (Khabarovsk, September 27-29, 2011). In 2 volumes Khabarovsk: Mining Institute FEB of the RAS, (2011). -Vol. 1. - P. 110-117 [In Russian].

7. D. V. Sidorov, M. I. Potapchuk, A. V. Sidlyar. Notes of the Mining Institute (2018). Vol. 234 [In Russian].

8. A. V. Sidlyar, M. I. Potapchuk. Problems of the mineral management (2017). - No. 1 (12). - P. 102-110 [In Russian].

9. A. V. Sidlyar, M. I. Potapchuk, A. A. Tereshkin. Mining Information and Analytical Bulletin. (2017). - No. 7. -P. 184-194 [In Russian]. 